\title{
Effective Incentive for Knowledge Workers in the Post- Epidemic Era
}

\author{
Yunfei $\mathrm{Xu}^{1, *}$ Han Wang ${ }^{2}$ Jian Zhao ${ }^{3}$ Dan Wang ${ }^{4}$ \\ 1,2,3,4 State Grid Energy Research Institute Co. LTD, Changping, 102209, Beijing, China \\ ${ }^{*}$ Corresponding author. Email: xuyunfei@sgeri.sgcc.com.cn
}

\begin{abstract}
With the vigorous development of knowledge economy, talents, especially high-quality talents represented by knowledge workers, have become the key to the survival and development of enterprises. In essence, the competition between enterprises is the competition between talents, especially knowledge workers. The importance of knowledge workers is becoming increasingly prominent, and the management and incentive of knowledge workers become the top priority. Based on the requirements of the fast-growing economy and the characteristics of knowledge workers, this paper discussed the incentive factors affecting knowledge workers, clarified the problems existing in the incentive of current knowledge workers, and provided targeted incentive measures in order to provide basis and reference for the effective incentive of knowledge workers.
\end{abstract}

Keywords: Knowledge economy, Knowledge workers, Incentives

\section{INTRODUCTION}

With the global spread of COVID-19, the world economy is in a highly sensitive period. The rise of knowledge-based economy based on knowledge capital is rapidly changing the production structure and relations of human society. Knowledge workers, as the main force in the era of knowledge economy, play a great role in promoting enterprises' innovation activities, rational allocation of various production factors and enhancing enterprises' competitiveness. With the development of China's industrialization, the proportion of knowledge workers in enterprises is increasing. In some enterprises, the proportion of knowledge workers reaches $100 \%$. The contribution of knowledge workers to the development of enterprises is often decisive. Effective incentives for knowledge workers can improve their work enthusiasm and creativity, change employees' work attitude, and thus improve work quality and performance [1]. It will also improve the organizational identification of knowledge workers, provide guarantee for the long-term development of the enterprise, and promote the common growth and development of the enterprise and employees. Therefore, it is particularly important to motivate knowledge workers and discover their full potential [2].

\section{THE DEFINITION AND CHARACTERI- STICS OF KNOWLEDGE WORKERS}

\subsection{The Definition of Knowledge Workers}

Peter Drucker defined the connotation of knowledge worker as "those who master and use symbols and concepts, and work with knowledge or information". Knowledge workers can not only use modern science, technology and knowledge to improve production efficiency, but also have a strong ability to learn knowledge and innovation [3]. According to Francis Herreby, knowledge workers are those who use their brains more than their hands to create wealth. Woodruff, the father of Coca Cola, defined knowledge workers as those who possess knowledge and apply the knowledge they have to carry out creative work. The standard to measure knowledge workers should be innovation, and innovation is the biggest characteristic of knowledge workers. Through a lot of investigation and study, AXA consulting firm defined knowledge workers as: "the knowledge workers with input of intelligence, creativity, and authority to complete the work, a knowledge-based staff mainly includes the following people: professionals, has a try to counseling professionals, senior manager of professional skills".

It is generally believed that knowledge workers are those who create more value with their wisdom than 
with their hands. They use knowledge and information to bring capital appreciation to the enterprise or organization and realize sustainable development of the enterprise. From the above definition, we can conclude that knowledge workers are those who create value for the company through their own knowledge, skills and information, and have more brains than hands to create value. Knowledge workers rely on knowledge as a means of making a living. They have stronger professional skills, a more independent and open way of thinking, and are more motivated and eager to learn. They have a clear career development plan, pay more attention to personal ability development and improvement, and attach great importance to leadership training.

\subsection{The Characteristics of Knowledge Workers}

\subsubsection{Strong Achievement Motivation and Respect Need}

Knowledge workers have higher education level, higher personal quality and higher level of demand. According to Maslow's hierarchy of needs theory, the needs of knowledge workers are complex and mainly focus on higher levels such as respect and selfactualization. The demand structure of knowledge workers is a kind of mixed and alternating demand structure. In addition to the high salary representing personal achievements and personal reputation and status in the society, they are also very concerned about their own ability improvement and career development opportunities. They attach importance to the update and supplement of knowledge and pay more attention to the development of their own career. They have a strong sense of achievement, often pursue personal achievements, hope to achieve their own value, social recognition. They are passionate about challenging work as a way to fulfill themselves. They are more eager for democracy and freedom, demanding more autonomy, a relaxed atmosphere throughout the organization, and being able to work in ways they think are effective [4].

\subsubsection{Knowledge Workers Are the Owners of Knowledge Capital}

The essential difference between knowledge workers and non-knowledge workers is that the former owns the means of production, namely knowledge workers are the owners of knowledge capital. Knowledge workers' dependence on the organization is obviously lower than that of other employees. At the same time, because the greatest value of knowledge workers lies in the possession of knowledge, the obsolescence and aging of knowledge will lead to the depreciation of the value of knowledge workers, and they are not competent for the work of this major. Therefore, in order to maintain and increase the value of their own knowledge capital, knowledge renewal has become a strong desire of knowledge workers.

\subsubsection{Autonomy and Creativity}

Most knowledge workers have higher education, professional skills, formal professional education and training. Their work ability is stronger, incline to think independently, study deeply, undertake creative activity. Strong sense of self-management, emphasizing selfguidance, self-management and self-development in work. Engaged in creative work, dealing with new situations and problems that may come up at any time in an uncertain and uncertain working environment.

\subsubsection{The Work Performance Is Difficult to Measure}

Knowledge workers are mainly engaged in thinking knowledge work relying on the brain, the labor process is often invisible, and may occur at any time and any place, work uncertainty is strong. It is difficult for knowledge workers to directly monitor their work process and hard to measure their work performance.

\subsubsection{High Turnover Rate}

Generally, employees tend to value stable work and security, while knowledge workers pay more attention to personal growth and development and pursue the realization of personal self-value, which makes knowledge workers easy to flow to different enterprises that can better give play to their potential and realize their life value.

\section{THE INCENTIVE DEMAND OF KNOWLEDGE WORKERS}

\subsection{Research on Incentive Factors of Knowledge Workers}

In 1989, Mahan Tempe, a famous American knowledge management expert, made a pioneering study on the incentive strategies of knowledge workers. Mahan Tempe found four motivating factors for knowledge workers through a lot of empirical research: individual growth, work autonomy, business achievement and financial wealth. The study ranked the importance of these four motivators based on survey data. As a result, individual growth accounts for $33.74 \%$, work autonomy accounts for $30.51 \%$, business achievement accounts for $28.69 \%$ and money wealth accounts for $7.06 \%$. Mahan Temp believes that while money is important to employees, it is more effective in motivating them if it meets their needs for personal growth, work autonomy, and business achievement. In 1998, AXA consulting company with the Australian institute of management research has analyzed the 
Australian industry, American and Japanese industries of 858 employees, including 160 knowledge workers), lists the "knowledge staff incentive factors" in the top five incentive factors, respectively is: the nature of the remuneration, working relationship with your colleagues, promotion, and influence the decision. Among them, knowledge workers pay more attention to the nature of work, relationship with colleagues and three factors that influence decision-making than nonknowledge workers. In contrast, knowledge workers pay less attention to job security and customer relationship than other types of employees. In 2001, Zhang \& Peng (2001) invested knowledge workers in Chinese hightech enterprise and concluded that the incentive factors of knowledge workers: compensation play accounted for $31.88 \%, 23.91 \%$ of personal growth and development, challenging work $(10.145 \%)$, the development prospect of the company accounted for $7.975 \%$, security and stability work accounted for $6.52 \%$.

Due to the differences in economic development and cultural environment, different countries or even different regions of the same country, or the same region in different time periods, the degree of incentive factors to the industry of knowledge workers is not the same. But in general, knowledge workers are motivated by a variety of factors, both material and nonmaterial, and they value personal growth, competence, and selfworth and growth more than non-knowledge workers [5]. From the above studies, it can be seen that in addition to salary, other factors are also very important for the incentive factors of knowledge workers finally determined by domestic and foreign researches.

\subsection{Motivation for Knowledge Workers}

Based on the research at home and abroad, the motivation factors of knowledge employees are mainly as follows: salary and welfare, work challenge, work autonomy, individual growth and individual sense of honor.

Compensation and benefits: include salary, bonus, other benefits, such as social insurance and housing fund, housing subsidy, transportation subsidy, etc.

Job Challenge: Refers to a job that is testing the physical and intellectual capacity of employees. This is mainly reflected in two aspects. On the one hand, work is not repetitive. For example, some assembly line work is repetitive every day, which is easy to make people tired. On the other hand, work requires effort to be done. If a job can be done with only $50 \%$ effort, then the job is not challenging.

Job autonomy: Employees are free to take control of their own work and incorporate their own ideas into it. They don't like to be controlled too much.Want more mandates.
Individual growth: Employees can gain personal growth from this job, which includes four aspects: expansion of knowledge, improvement of ability, increase of experience and promotion of position.

Individual sense of honor: mainly refers to the recognition of subordinates by superiors and the recognition of other employees.

The above five incentive factors constitute the incentive system of knowledge-based employees. Therefore, the design of knowledge-based incentive system must start from their needs, and all aspects of the needs are taken into account, only in this way, the company's incentive measures can really take into effect.

\section{PROBLEMS EXISTING IN THE MOTIVATION OF KNOWLEDGE WORKERS}

At present, the management and motivation of knowledge employees generally exist the following three problems and deficiencies.

\subsection{The Solidification of Management Mode Lacks Innovation}

In the actual process of enterprise management, enterprises that use traditional administrative intervention mode still occupy the majority. Although this mode provides some convenience for the management of employees, it restricts the creativity of employees to a certain extent and makes their productivity fail to be given full play. At work, knowledge workers pay special attention to their changing roles, autonomy and participation. Knowledge workers advocate doing their work in a way they approve of. However, many enterprises have not adjusted the management mode timely according to the characteristics of knowledge employees, and still treat knowledge employees in the traditional management way. It carries on the "paternalistic" management, namely supervises too much, too carefully, neglects its personalized demand, thus suppresses the autonomy of knowledge workers. And the traditional management mode for knowledge workers, lack of scientific and flexibility, not only can not provide knowledge workers with a suitable working environment, but also will limit their creativity, and ultimately bring negative impact to the development of the enterprise [6].

\subsection{Imperfect Self-Enabling Incentive Mechanism}

Incentive mechanism refers to the process of maximizing employees' commitment to the organization and work through specific methods and management systems. Once the incentive mechanism is formed, it 
will act on the organizational system itself, make the organizational function in a certain state, and further affect the survival and development of the organization. Incentive mechanism is very important to retain knowledge workers. In the current fierce human capital competition, human resource managers have realized the importance of attracting, retaining and motivating knowledge workers. However, some enterprises have not understood that giving knowledge workers the opportunity to motivate themselves is a good way to motivate them. Not only the use of material means or spiritual pressure is a good incentive means, these means may lead to the enterprise to take excessive incentive measures. It is not effective to stop staff turnover, we must find the crux of staff turnover from the source, and solve it, so as to reduce the outflow of knowledge workers.

\subsection{Emphasize That Organizational Empowerment Ignores Individuals, Resulting in Insufficient Trust In Employees Due To Less Decentralization}

With the rise of the idea of empowerment, empowerment is gradually accepted by most enterprises. However, at present, corporate empowerment is mostly concentrated in the group and an important organization of the industry, and power is only delegated to a certain department of the group and the enterprise. Although companies are consciously willing to empower, the idea of management itself -- group empowerment -- can reduce costs. Perhaps out of a distrust of employees, the power is not devolved upon them after all

\section{EFFECTIVE INCENTIVE STRATEGIES FOR KNOWLEDGE WORKERS}

On the basis of understanding the characteristics and incentive factors of knowledge workers, and aiming at the problems existing in the incentive of knowledge workers, enterprise managers can focus on the following four aspects to constantly improve and perfect, and strengthen the incentive to knowledge workers.

\subsection{Realize The Diversification of Value Distribution Elements}

Compensation is no longer the most important goal that knowledge workers hope to get from their work. Likewise, compensation incentive should not be the only value element for enterprises to motivate knowledge workers. This doesn't mean that compensation incentive is no longer important, but compensation incentive as a basic means of value distribution, still need to be paid attention to, but enterprises can do more.

Maslow's hierarchy of needs tells us that humans have both material and nonmaterial needs. As material needs are met, nonmaterial needs become more important. Therefore, enterprises also need to pay attention to the importance of "opportunity" to knowledge workers. Opportunity is a more influential factor that motivates knowledge workers to create, disseminate and apply knowledge. Opportunities can take many forms, such as participation in decisionmaking, more responsibility, opportunities for personal growth, greater freedom and authority at work, more interesting work, and diverse work activities. These "internal rewards" are more attractive to knowledge workers.

\subsection{Create an Independent and Innovative Corporate Cultural Atmosphere}

It is often said that innovation needs "soil", otherwise innovation will be like a tree without soil, it is difficult to survive for a long time. Knowledge workers are a group of people with high autonomy and creativity. Only in the cultural atmosphere of independence and innovation can they give full play to their own characteristics and create better products and services. Enterprises should recognize and respect the characteristics of knowledge workers, establish and cultivate an independent, collaborative, innovative and dynamic corporate culture, provide challenging work for employees, tolerate employees' mistakes, and encourage communication among employees, so as to cultivate knowledge workers more conducive to their development "soil".

\subsection{Improve The Career Management Plan}

Companies can easily get into trouble when it comes to "employee development" and "employee retention". On the one hand, enterprises hope that their employees can be excellent enough to create higher value for the enterprise, so they try to take various measures to improve the ability of employees and promote them to realize their self-value. On the other hand, the enterprise also hopes that enough excellent employees can "take root in the enterprise" and continue to contribute to the development of the enterprise. In order to solve this dilemma, enterprises can conduct "career management" for knowledge-based employees. By helping employees make career plans based on their interests, abilities and specialties as well as the needs of the enterprise, enterprises can closely combine their future development with the future development of the enterprise. Then, by helping employees to carry out their career plans, knowledge employees' activities of pursuing personal development are effectively integrated with their contributions to the enterprise, so as to not only stimulate knowledge employees' selfrealization aspirations, but also to find the joint point of common development between individuals and enterprises. 


\subsection{Implement Differentiated Incentives}

Knowledge workers may have different demands at different positions, management levels and career development stages. Therefore, it is necessary to understand the differentiated demands of knowledge workers and conduct differentiated incentives. For example, the incentive needs of knowledge employees at different management levels may be different: for high-level knowledge employees, their level of needs is relatively high and they are more in pursuit of the realization of personal value and personal development opportunities. When encouraging them, we should focus on their spiritual feelings, identification and integration of corporate culture, job achievement, full authorization, social recognition and respect, etc. Middle-level knowledge workers may be leaders in a team, and they should be encouraged in three aspects: firstly, fairness of salary and growth opportunities; secondly, training opportunities and improvement of management and business capabilities; thirdly, full authorization and acquisition of corresponding rights and responsibilities.

For grassroots knowledge workers, the level of demand is relatively lower, and their power and influence are relatively limited. Therefore, the focus of incentive is salary incentive, cultural incentive, training incentive and spiritual incentive.

\section{CONCLUSION}

The growth environment and personality characteristics of knowledge-based employees are very different from those of the traditional generation. Although the enterprise incentive mechanism has become a set of system up to now, certain achievements have been made in the process of practice. In recent years, a lot of salary management theories have emerged at home and abroad, but most of them are about general incentive at large enterprises, which are not suitable and targeted at knowledge workers. After studying literature and the management content problems, and analyzing the general situation of knowledge workers' working ability, this paper puts forward relevant solutions and suggestions in view of these phenomena. Considering the relevant situation of small and medium-sized enterprises, select and formulate their own unique wage system, increase the competitive rate of enterprises, and finally achieve the maximum profit of enterprises.

\section{ACKNOWLEDGMENTS}

This research was supported by the State Grid Corporation of China science and technology project "Research on talent supply and demand analysis model and supply strategy suitable for company strategy".

\section{REFERENCES}

[1] S.P. Tsai. Innovative behaviour of knowledge workers and social exchange attributes of financial incentive: implications for knowledge management. 2018, 22(8):1712-1735.

[2] A.S. Tsui, J.L. Pearce, L.W. Porter, \& A.M. Tripoli. Alternative approcahes to the employeeorganizational relationship: Does investment in employee pay off[M]. Academy of Management Journal,1997.

[3] P. Drucker. The Age of Discontinuity. 2017.

[4] P. Drucker. Managing for the Future. 2013.

[5] C.J. Zhu, M. Warner. The emergence of Human Resource Management in China: Convergence, divergence and contextualization. 2019, 29(1):8797.

[6] A Newman, Q. Miao, P.S. Hofman, et al. The impact of socially responsible human resource management on employees' organizational citizenship behaviour: the mediating role of organizational identification. 2016, 27(4):440-455. 